Vol. 6 No. 1; Juni 2019

\title{
Pengaruh Suhu Pengeringan Terhadap Kualitas Produk Gula Semut dari Nira
}

The Effect of Drying Temperature in the Quality of Brown Sugar from Sugar Palm Sap

\author{
Meldayanoor $^{1}$, Adzani Ghani Ilmannafian', Fitria Wulandari ${ }^{1}$ \\ ${ }^{1}$ Jurusan Teknologi Industri Pertanian, Politeknik Negeri Tanah Laut, Jl. A.Yani, Km.6, \\ Desa. Panggung, kec. Pelaihari, kab Tanah Laut, Kalimantan Selatan 70815.Indonesia. \\ Email: meldayanoor@gmail.com
}

Naskah diterima: 01 April 2019; Naskah disetujui : 22 April 2019

\begin{abstract}
Sugar Palm trees are widely found in Kabupaten Tanah Laut, especially in Guntung Besar and Ranggang. Palm trees produce sap which is processed by traditional method. In order to improve the quality this study was conducted to make brown sugar with variations in drying temperature. This study used an experimental method with 4 treatments namely temperature drying of $100^{\circ} \mathrm{C}, 75^{\circ} \mathrm{C}, 50^{\circ} \mathrm{C}$, and control (without temperature drying). The tests used in this study were $\mathrm{pH}$ test, moisture content test, ash content test and organoleptic test. The results showed that the $\mathrm{pH}$ value of the sap used ranged from 6-7 and brown sugar with temperature drying of $100^{\circ} \mathrm{C}$ was the most preferred with a moisture content value of $2,97 \%$ and ash content value of $1,98 \%$. This value has fulfilled SNI 01-3743-1995.
\end{abstract}

Keywords: ash content, brown sugar, moisture content

\begin{abstract}
ABSTRAK
Pohon aren banyak terdapat di Kabupaten Tanah Laut, khususnya di daerah Guntung Besar dan daerah Ranggang. Pohon aren menghasilkan nira yang diolah menjadi gula cetak atau gula merah. Agar gula merah memiliki kualitas yang lebih baik dan memiliki nilai tambah maka dilakukan pembuatan gula semut. Tujuan penelitian ini adalah membuat gula semut dengan variasi suhu pengeringan. Penelitian ini menggunakan metode eksperimental dengan 4 perlakuan yaitu pengeringan suhu $100^{\circ} \mathrm{C}$, $75^{\circ} \mathrm{C}, 50^{\circ} \mathrm{C}$, dan kontrol (tanpa pengeringan suhu). Uji yang digunakan dalam penelitian ini adalah uji $\mathrm{pH}$, uji kadar air, uji kadar abu, dan uji organoleptik. Hasil penelitian menunjukkan nilai $\mathrm{pH}$ nira yang digunakan berkisar 6-7 dan gula semut dengan pengeringan suhu $100^{\circ} \mathrm{C}$ merupakan produk yang paling disukai dengan nilai kadar air yaitu $2,97 \%$ dan nilai kadar abu yaitu $1,98 \%$. Nilai tersebut sudah memenuhi SNI 013743-1995.
\end{abstract}

Kata kunci: kadar abu, gula semut, kadar air 


\section{PENDAHULUAN}

Gula merupakan komoditi penting bagi masyarakat Indonesia bahkan bagi masyarakat dunia. Peranan gula sangat penting yaitu sebagai pemanis utama dalam industri makanan dan minuman. Gula merah merupakan salah satu pemanis alami yang tidak mengandung kimia berbahaya bagi tubuh (Mashud, 2011). Pohon aren banyak terdapat di Kabupaten Tanah Laut, khususnya di daerah Guntung Besar dan daerah Ranggang. Namun pembuatan air aren di daerah tersebut hanya dibuat menjadi gula cetak/gula merah karena pembuatannya lebih praktis.

Gula merah jika disimpan pada suhu kamar akan mengakibatkan gula merah mudah mencair. Keadaan ini dapat mengakibatkan kerugian bagi para pedagang dan dapat dicegah dengan mengolah gula tersebut menjadi gula semut. Gula semut adalah gula aren yang berbentuk butir kecil - kecil yang dapat dibuat dari nira yaitu suatu air aren yang masih segar langsung dimasak didalam wajan dengan cara dipanaskan sampai mengering dan warnanya berubah menjadi coklat (Pratama, 2015).

Gula semut berfungsi sebagai pemanis dan pemberi warna coklat. Kualitas gula semut yang dihasilkan sangat ditentukan oleh bahan baku utamanya yaitu nira yang masih segar langsung dari pohonnya. Menurut Mustaufik (2007) bentuk gula semut yang serbuk menyebabkan gula mudah larut sehingga praktis dalam penyajian, mudah dikemas dan dibawa, serta daya simpan yang lama karena memiliki kadar air yang rendah. Selain memiliki kelebihan, gula semut memiliki kelemahan yaitu proses pembuatan yang tidak mudah, dan bahan bakunya harus masih segar dan tidak masam. Permasalahan yang muncul pada gula semut yang terdapat di pasaran adalah memiliki $\mathrm{pH}$ yang terlalu rendah. $\mathrm{pH}$ atau derajat keasaman yang terdapat pada bahan baku sangat mempengaruhi proses kristalisasi pembuatan gula semut karena adanya jumlah gula reduksi yang terbentuk.

Berdasarkan latar belakang diatas, maka diperlukan pengolahan gula semut dari bahan utama nira yang masih segar, tidak asam, kemudian langsung dimasak hingga kadar airnya berkurang dan warnanya berubah menjadi kecoklatan sehingga dihasilkan gula semut yang $100 \%$ alami tanpa campuran bahan lainnya. 


\title{
METODE PENELITIAN
}

\section{Tempat}

Penelitian ini dilakukan di Laboratorium Teknologi Pangan dan Laboratorium Pengujian Laboratorium Bioproses, Jurusan Teknologi Industri Pertanian Politeknik Negeri Tanah Laut.

\begin{abstract}
Alat dan Bahan
Alat yang digunakan adalah kompor, wajan, oven listrik, piring kecil, ayakan, sendok, neraca analitik, loyang kecil, cawan porselin, sarung tangan kain, pisau, hand sealer, nampan dan alat tulis kerja. Bahan yang digunakan untuk pembuatan gula semut adalah nira
\end{abstract}

\section{Proses Pembuatan Gula semut}

Pertama disiapakan nira yang masih segar dan peralatan yang diperlukan. Setelah semua siap, dibersihkan alat - alat tersebut sampai bersih lalu ditiriskan, kemudian nira dimasukan kewajan dimasak dengan waktu +2 jam hingga kadar airnya berkurang, teksturnya mengental dan warnanya berubah menjadi kecoklatan muda lalu diaduk terus hingga kering sampai berbentuk butiran kecil sambil dihaluskan menggunakan mortar alu hingga halus, kemudian diayak agar ukurannya seragam, butiran gula semut masih terlihat basah sehingga dilakukan pengurangan kadar air dengan menggunakan pengovenan dengan ketetapan waktu selama 1 jam yang dilakukan dengan berbagai suhu yang berbeda - beda yaitu $50^{\circ} \mathrm{C}, 75^{\circ} \mathrm{C}$ dan $100^{\circ} \mathrm{C}$ menggunakan oven listrik, didiamkan sampai dingin. Lalu dikemas menggunakan kemasan yang telah disediakan.

\section{Analisis Uji}

Gula semut dengan pengeringan suhu yang berbeda - beda yaitu dengan suhu $50^{\circ} \mathrm{C}$, $75^{\circ} \mathrm{C}$ dan $100^{\circ} \mathrm{C}$ dengan ketetapan waktunya yaitu selama 1 jam, selanjutnya akan dilakukan analisis uji kadar air, kadar abu, kadar rendemen dan uji organoleptik. Pembuatan Gula semut ini dilakukan dengan 4 perlakuan 3 kali ulangan, dan uji organoleptic yang dianalisis secara statistik dengan menggunakan Uji ANOVA. 


\section{Uji pH}

Pengujian $\mathrm{pH}$ ini dilakukan pada tiap - tiap pengulangan yaitu pengulangan 1,2 dan 3, untuk mengetahui apakah nira tersebut dapat dibuat gula semut atau tidak, pengujian $\mathrm{pH}$ dilakukan dengan menggunakan kertas $\mathrm{pH}$. Penggunaan kertas $\mathrm{pH}$ yaitu dengan cara nira yang telah diambil/disadap dari pohon aren di masukan kedalam botol atau wadah yang telah disediakan, kertas $\mathrm{pH}$ langsung dimasukan kedalam nira tersebut, diangkat dan diamati warna dari kertas $\mathrm{pH}$ tersebut, dicocokan dengan warna manakah yang sesuai dengan nilai $\mathrm{pH}$ yang ada dilembar kertas $\mathrm{pH}$.

\section{Uji Kadar Air}

Pengujian Kadar Air menggunakan metode oven (SNI 01-2891-1992). Vochdoos kosong dimasukkan oven pada suhu $105^{\circ} \mathrm{C}$ selama 1 jam kemudian dinginkan dalamdesikator dan ditimbang (W1). Sampel Gula semut yang sudah ditimbang dengan berat 2 gram (W) dimasukkan dalam vochdoos, dan dikeringkan dalam oven pada suhu $105^{\circ} \mathrm{C}$ selama 3 jam. Sampel dalam vochdoos didinginkan dalam desikator kemudian ditimbang sampai berat tetap (W2). Kadar Air ditentukan dengan rumus:

$$
\% \text { Kadar Air }=\frac{(w 1+w)-w 2}{w} \times 100 \%
$$

\section{Uji Kadar Abu}

Pengujian Kadar Abu dengan metode Tanur (SNI 01-2891-1992). Crusibel kosong dimasukkan dalam tanur pada suhu $550^{\circ} \mathrm{C}$ selama 1 jam, kemudian didinginkan dalam desikator dan ditimbang (W1). Sampel ditimbang dengan bobot 2 gram (W) dimasukkan dalam crusibel kosong, kemudian dimasukkan dalam tanur pada suhu $550^{\circ} \mathrm{C}$ selama 4 jam. Setelah waktu dalam tanur tercapai sampel didinginkan dalam desikator dan ditimbang (W2). Kadar Abu ditentukan dengan rumus:

$$
\% \operatorname{Kadar} \mathrm{Abu}=\frac{(w 2+w 1)}{w} \times 100 \%
$$

\section{Uji Organoleptik}

Uji organoleptik dilakukan oleh 15 panelis untuk mengetahui kesukaan panelis terhadap warna, aroma dan tekstur dari masing-masing perlakuan produk gula semut. Hasil penilaian panelis dianalisis menggunakan uji ANOVA dan uji lanjut DMRT untuk melihat perbedaan setiap perlakuan 


\section{HASIL DAN PEMBAHASAN}

\section{A. Uji pH}

Nira sangat berpotensi untuk dijadikan gula karena nira mengandung komponen gula yang dominan dalam bentuk sukrosa. Kandungan sukrosa yang dominan diantara kandungan bahan kimia non-air lainnya menjadikan nira sebagai sumber gula yang sangat potensial. Unsur sukrosa pada nira relatif cepat terurai dengan adanya aktifitas mikroba, mengakibatkan terjadinya perubahan $\mathrm{pH}$ menjadi asam. Nira yang sudah masam tidak cocok untuk pembuatan gula granular karena gula tidak mengkristal.

Berdasarkan hasil uji $\mathrm{pH}$, nilai $\mathrm{pH}$ pada pembuatan gula semut pada pengulangan pertama adalah 7, pengulangan kedua dengan nilai $\mathrm{pH} 6$ dan pengulangan ketiga dengan nilai $\mathrm{pH} 6$, nilai $\mathrm{pH}$ tersebut didapatkan dari air aren yang baru diambil atau disadap dari pohonnya. Hal ini sesuai dengan pernyataan Mohandri dan Wantiman Sus (2010), nira yang digunakan sebagai bahan baku untuk pembuatan gula semut memiliki pH 6 - 7 .

\section{B. Uji Kadar Air}

Uji kadar air dilakukan untuk mengetahui sesuai atau tidaknya nilai kadar air dari produk gula semut dengan SNI 01-3743-1995. Nilai kadar air menentukan masa simpan produk gula semut. Nilai kadar air yang tinggi dapat menyebabkan mudahnya bakteri tumbuh, sedangkan nilai kadar air yang rendah dapat memperpanjang umur simpan suatu produk (Winarno, 2007). Berikut merupakan nilai rata-rata kadar air dari 3 kali pengulangan untuk setiap perlakuan.

\section{Tabel 1. Nilai Uji Kadar Air}

\begin{tabular}{cc}
\hline Suhu Pengeringan & Nilai kadar Air \\
\hline $100^{\circ} \mathrm{C}$ & $2,97 \%$ \\
$75^{\circ} \mathrm{C}$ & $3,06 \%$ \\
$50^{\circ} \mathrm{C}$ & $3,09 \%$ \\
Kontrol & $3,71 \%$ \\
\hline
\end{tabular}

Berdasarkan Tabel 1, kadar air terendah pada perlakuan suhu pengeringan $100^{\circ} \mathrm{C}$ dengan nilai kadar air 2,97 \%, dan kadar air tertinggi yaitu pada perlakuan kontrol dengan nilai $3,71 \%$. Rendahnya kadar air disebabkan adanya perlakuan pengovenan karena didalam pengovenan terjadi proses pengeringan sehingga kadar air nya berkurang, tingginya kadar air pada kontrol disebabkan tidak adanya perlakuan pengeringan. Nilai 
kadar air yang memnuhi SNI 01-3743-1995 (maksimal 3 \%) adalah gula semut pada suhu pengeringan $100^{\circ} \mathrm{C}$ dengan nilai kadar air $2,97 \%$.

\section{Uji Kadar Abu}

Uji kadar abu dilakukan untuk mengetahui nilai kadar abu dari produk gula semut, kemudian dibandingkan dengani nilai SNI 01-3743-1995. Kadar abu termasuk salah satu faktor penentu mutu gula semut. Kadar abu yang tinggi dapat menurunkan mutu gula semut. Peningkatan kadar abu gula semut disebabkan adanya peningkatan jumlah senyawa mineral anorganik pada produk seperti garam fosfat, karbonat, khlorida, sulfat, dan nitrat (Zuliana, dkk, 2016). Penentuan kadar abu dalam suatu bahan dapat diukur dengan metode pengabuan langsung yaitu menggunakan panas yang tinggi dan oksigen yang bertindak sebagai oksidator. Penggunaan suhu yang tinggi akan membakar bahan bahan organik dan menyisakan residu berupa zat anorganik atau mineral. Kadar abu dihitung dengan menimbang sisa hasil pembakaran bahan pada suhu tinggi $\left(550{ }^{\circ} \mathrm{C}\right)$ (Winarno, 2007). Berikut merupakan nilai rata-rata kadar abu dari 3 kali pengulangan untuk setiap perlakuan:

\begin{tabular}{cc}
\multicolumn{2}{c}{ Tabel 2. Hasil Nilai Uji Kadar Abu } \\
\hline Suhu Pengeringan & Nilai kadar Abu \\
\hline $100^{\circ} \mathrm{C}$ & $1,98 \%$ \\
$75^{\circ} \mathrm{C}$ & $2,06 \%$ \\
$50^{\circ} \mathrm{C}$ & $2,05 \%$ \\
Kontrol & $2,53 \%$ \\
\hline
\end{tabular}

Pengukuran kadar abu dapat menjadi parameter baik atau tidaknya suatu proses pengolahan dan kemurnian dari gula semut. Berdasarkan Tabel 2, kadar abu terendah pada perlakuan suhu pengeringan $100^{\circ} \mathrm{C}$ dengan nilai 1,98\% dan kadar abu tertinggi yaitu pada perlakuan kontrol dengan nilai 2,53 \%. Berdasarkan hasil tersebut, nilai kadar abu yang memenuhi SNI 01-3743-1995 (maksimal 2 \%) adalah gula semut pada suhu pengeringan $100^{\circ} \mathrm{C}$ dengan nilai kadar abu $1,98 \%$.

\section{Uji Organoleptik}

Uji organoleptik pada brown sugar ini dilakukan oleh 15 orang panelis. Sampel brown sugar yang diuji ada 12 yang terdiri dari 4 perlakuan dengan masing-masing perlakuan terdiri dari 3 pengulangan. Panelis memberi nilai kesukaan terhadap aroma, rasa, warna dan tekstur. Berikut merupakan penilaian panelis terhadap produk gula semut 
Tabel 3. Hasil Uji Organoleptik

\begin{tabular}{ccccc}
\hline Suhu Pengeringan & Warna & Aroma & Rasa & Tekstur \\
\hline $100^{\circ} \mathrm{C}$ & $84,89 \%$, & $80 \%$ & $89,78 \%$ & $70,67 \%$, \\
$75^{\circ} \mathrm{C}$ & $80 \%$ & $80 \%$ & $80 \%$ & $84,44 \%$ \\
$50^{\circ} \mathrm{C}$ & $67,56 \%$ & $68,44 \%$, & $80 \%$ & $65,86 \%$ \\
Kontrol & $75,11 \%$ & $76,89 \%$, & $93,78 \%$ & $71,56 \%$, \\
\hline
\end{tabular}

\begin{tabular}{ll}
\hline Keterangan: & \\
$0 \%-20 \%$ & $=$ Sangat Tidak Suka \\
$20 \%-40 \%$ & $=$ Tidak Suka \\
$40 \%-60 \%$ & $=$ Agak Suka \\
$60 \%-80 \%$ & $=$ Suka \\
$80 \%-100 \%$ & $=$ Sangat Suka
\end{tabular}

Berdasarkan Tabel 3, panelis sangat menyukai warna, aroma, dan rasa gula semut dengan suhu pengeringan $100^{\circ} \mathrm{C}$. Penilaian panelis dianalisis menggunakan uji ANOVA, hasilnya menunjukkan bahwa suhu pengeringan tidak berpengaruh nyata terhadap kesukaan panelis terhadap warna, aroma, dan tekstur gula semut. Namun berpengaruh nyata terhadap kesukaan panelis terhadap rasa. Rasa yang paling disukai adalah gula semut dengan suhu pengeringan $100^{\circ} \mathrm{C}$ dan kontrol.

\section{KESIMPULAN}

Hasil penelitian menunjukkan nilai $\mathrm{pH}$ nira yang digunakan berkisar 6-7 dan gula semut dengan pengeringan suhu $100^{\circ} \mathrm{C}$ merupakan produk yang paling disukai dengan nilai kadar air yaitu 2,97\% dan nilai kadar abu yaitu 1,98\%. Nilai tersebut sudah memenuhi SNI 01-3743-1995.

\section{DAFTAR PUSTAKA}

Badan Standardisasi Nasional. (1992). Cara Uji Makanan dan Minuman SNI 01-28911992. Badan Standardisasi Nasional, Jakarta.

Badan Standardisasi Nasional. (1995). Gula Palma SNI 01-3743-1995. Badan Standardisasi Nasional, Jakarta

Mashud. (2011). Pembuatan Gula Semut Dari Bahan Baku Gula Kelapa Cetak Dengan Perbandingan Gula Tebu. Skripsi. Jurusan THP. Fakultas Teknologi Pertanian. INSTIPER Yogyakarta

Mustaufik dan H. Dwianti. (2007). Rekayasa Pembuatan Gula Kelapa Kristal yang Diperkaya dengan Vitamin A dan Uji Preferensinya kepada Konsumen. Laporan Penelitian. Peneliti Dosen Muda Dikti Jakarta. Jurusan Teknologi Pertanian Universitas Jenderal Soedirman. Purwokerto. 
Pratama, Ferry, dkk. (2015). Pembuatan Gula Kelapa Dari Nira Terfermentasi Alami (Kajian Pengaruh Konsentrasi Anti Inversi Dan Natrium Metabisulfit). Jurnal Pangan dan Agroindustri Vol. 3 No 4 p.1272-1282,

Wantiman S., Mohandri (2010) Penentuan pH Air Aren. Jurnal Teknologi Pertanian. Bandung.

Winarno, F. G., (2007).Kimia Pangan dan Gizi. PT Gramedia Pustaka Utama. Jakarta. 253 hal.

Zuliana, dkk, (2016). Pembuatan Gula Semut Kelapa (Kajian pH Gula Kelapa Dan Konsentrasi Natrium Bikarbonat. Jurnal Pangan Dan Agroindustri Vol. 4 No 1 P.109-119, Januari 2016. 